\title{
REVIEW
}

\section{The evolution of clinical trials for infant acute lymphoblastic leukemia}

\author{
RS Kotecha ${ }^{1,2,3}$, NG Gottardo ${ }^{1,2,3}$, UR Kees ${ }^{2}$ and CH Cole ${ }^{1,2,3}$
}

Acute lymphoblastic leukemia (ALL) in infants has a significantly inferior outcome in comparison with older children. Despite initial improvements in survival of infants with ALL since establishment of the first pediatric cooperative group ALL trials, the poor outcome has plateaued in recent years. Historically, infants were treated on risk-adapted childhood ALL protocols. These studies were pivotal in identifying the need for infant-specific protocols, delineating prognostic categories and the requirement for a more unified approach between study groups to overcome limitations in accrual because of low incidence. This subsequently led to the development of collaborative infant-specific studies. Landmark outcomes have included the elimination of cranial radiotherapy following the discovery of intrathecal and high-dose systemic therapy as a superior and effective treatment strategy for central nervous system disease prophylaxis, with improved neurodevelopmental outcome. Universal prospective identification of independent adverse prognostic factors, including presence of a mixed lineage leukemia rearrangement and young age, has established the basis for risk stratification within current trials. The infant-specific trials have defined limits to which conventional chemotherapeutic agents can be intensified to optimize the balance between treatment efficacy and toxicity. Despite variations in therapeutic intensity, there has been no recent improvement in survival due to the equilibrium between relapse and toxicity. Ultimately, to improve the outcome for infants with ALL, key areas still to be addressed include identification and adaptation of novel prognostic markers and innovative therapies, establishing the role of hematopoietic stem cell transplantation in first complete remission, treatment strategies for relapsed/refractory disease and monitoring and timely intervention of late effects in survivors. This would be best achieved through a single unified international trial.

Blood Cancer Journal (2014) 4, e200; doi:10.1038/bcj.2014.17; published online 11 April 2014

\section{INTRODUCTION}

Acute lymphoblastic leukemia (ALL) is the most common malignancy occurring in children and adolescents, accounting for $\sim 20 \%$ of cancers in patients younger than 20 years of age. ${ }^{1,2}$ Remarkable therapeutic advances have been made since Sidney Farber first reported temporary remission in five children with acute leukemia using the folate antagonist, aminopterin, in $1948 .^{3}$ The 5 -year overall survival (OS) now exceeds $90 \%$, with significant improvements in survival for subgroups according to age, sex, race, immunophenotype and National Cancer Institute risk status. ${ }^{4}$ However, infants less than 1 year of age at diagnosis are the exception to this success. The initial modest improvement in survival following inception of cooperative group clinical trials has stalled with minimal gains over the past decade. ${ }^{4}$ This review encompasses the evolution of clinical trials for infant ALL, from the risk-adapted protocols of the past to the current collaborative infant-specific studies, and provides perspectives for improving outcome for infant ALL in the future.

\section{THE PAST: RISK-ADAPTED THERAPY ON CHILDHOOD LEUKEMIA STUDIES}

The first cooperative clinical trials for childhood leukemia were established in the $1950 \mathrm{~s}^{5}$ Initially all children were treated uniformly; however, it was soon recognized that certain clinical features at diagnosis had profound prognostic significance. The unfavorable prognosis carried by infants less than 1 year of age was identified following analysis of prognostic features from successive trials and registry data. ${ }^{6-8}$ This led to the strategy of risk adaptation within clinical trials, with the majority increasing the intensity of therapy delivered to infants by stratification to high-risk arms. Table 1 summarizes published outcomes for infants treated within childhood ALL studies. Although the number enrolled onto each study was limited by the rarity of infant $A L L$, and several studies did not differentiate infants by B or T-cell lineage, they were fundamental in demonstrating the poor event-free survival (EFS) and OS of infants within high-risk strata of childhood ALL studies.

Combined analysis of infants treated on successive childhood ALL protocols within individual study groups identified key biological and clinical prognostic features. Presence of a mixed lineage leukemia (MLL) rearrangement, ${ }^{9}$ hyperleukocytosis at presentation, ${ }^{10}$ absence of CD10 antigen, ${ }^{10}$ age $<6$ months at diagnosis ${ }^{11}$ and poor response to initial prednisone therapy ${ }^{11}$ were independently associated with an inferior outcome.

Despite suboptimal outcomes, this period in the history of clinical trials for infant ALL was pivotal in defining the foundations for future therapy, namely the need for infant-specific ALL protocols, delineation of prognostic categories to allow for risk stratification within infant ALL and a more unified approach between study groups to overcome limitations in accrual because of low incidence.

\footnotetext{
${ }^{1}$ Department of Haematology and Oncology, Princess Margaret Hospital for Children, Perth, Western Australia, Australia; ${ }^{2}$ Telethon Institute for Child Health Research, University of Western Australia, Perth, Western Australia, Australia and ${ }^{3}$ School of Paediatrics and Child Health, University of Western Australia, Perth, Western Australia, Australia. Correspondence: Dr RS Kotecha, Department of Haematology and Oncology, Princess Margaret Hospital for Children, GPO Box D184, Perth, Western Australia 6840, Australia. E-mail: rishi_k28@hotmail.com
}

Received 18 February 2014; accepted 20 February 2014 
Table 1. Summary of results for infants treated on childhood ALL protocols

\begin{tabular}{|c|c|c|c|c|c|c|}
\hline $\begin{array}{l}\text { Group } \\
\text { Country }\end{array}$ & Study & Year & $\begin{array}{l}\text { Number of } \\
\text { infants }\end{array}$ & $\begin{array}{l}\text { 5-Year } \\
\text { EFS (\%) }\end{array}$ & $\begin{array}{l}5-Y e a r \\
\text { OS (\%) }\end{array}$ & Reference \\
\hline $\begin{array}{l}\text { AIEOP } \\
\text { Italy }\end{array}$ & $\begin{array}{l}\text { AIEOP-ALL } 82 \\
\text { AIEOP-ALL } 88 \\
\text { AIEOP-ALL } 91 \\
\text { AIEOP-ALL } 95\end{array}$ & $\begin{array}{l}1982-1987 \\
1988-1992 \\
1991-1995 \\
1995-2000\end{array}$ & $\begin{array}{l}16 \\
16 \\
21 \\
31\end{array}$ & $\begin{array}{l}31.3 \\
31.3 \\
33.3 \\
51.6\end{array}$ & $\begin{array}{l}37.5 \\
56.3 \\
52.4 \\
57.6\end{array}$ & 88 \\
\hline $\begin{array}{l}\text { BFM } \\
\text { Germany, Austria, Switzerland }\end{array}$ & $\begin{array}{l}\text { ALL-BFM } 81 \\
\text { ALL-BFM } 83 \\
\text { ALL-BFM } 86 \\
\text { ALL-BFM } 90 \\
\text { ALL-BFM } 95\end{array}$ & $\begin{array}{l}1981-1983 \\
1983-1986 \\
1986-1990 \\
1990-1995 \\
1995-2000\end{array}$ & $\begin{array}{r}9 \\
13 \\
34 \\
60 \\
33\end{array}$ & $\begin{array}{l}55.6 \\
23.1 \\
38.2 \\
51.6 \\
38.5\end{array}$ & $\begin{array}{l}100 \\
46.2 \\
50.0 \\
58.3 \\
44.7\end{array}$ & 89 \\
\hline $\begin{array}{l}\text { CCG } \\
\text { USA }\end{array}$ & CCG-192P & 1982-1984 & 27 & $36.0^{\mathrm{a}}$ & - & 13 \\
\hline $\begin{array}{l}\text { EORTC-CLG } \\
\text { France, Belgium, Portugal }\end{array}$ & $\begin{array}{l}58831 \\
58832 \\
58881\end{array}$ & $\begin{array}{l}1983-1989 \\
1989-1998\end{array}$ & $\begin{array}{l}23 \\
60\end{array}$ & $\begin{array}{l}39^{b} \\
42.5\end{array}$ & - & 90 \\
\hline $\begin{array}{l}\mathrm{CPH} \\
\text { Czech Republic }\end{array}$ & $\begin{array}{l}\text { ALL-BFM } 83 \\
\text { ALL-BFM } 90\end{array}$ & $\begin{array}{l}1986-1990 \\
1990-1996\end{array}$ & $\begin{array}{l}14 \\
13\end{array}$ & $\overline{30.8}$ & $\overline{30.8}$ & $\begin{array}{l}92 \\
93\end{array}$ \\
\hline $\begin{array}{l}\text { DCOG } \\
\text { The Netherlands }\end{array}$ & $\begin{array}{l}\text { DCLSG-ALL-7 } \\
\text { DCLSG-ALL-8 }\end{array}$ & $\begin{array}{l}1988-1991 \\
1991-1997\end{array}$ & $\begin{array}{r}3 \\
13\end{array}$ & $\begin{array}{r}66.7 \\
0.0\end{array}$ & $\begin{array}{l}33.3 \\
15.4\end{array}$ & 94 \\
\hline $\begin{array}{l}\text { DFCl } \\
\text { Dana-Farber Cancer Institute, } \\
\text { USA }\end{array}$ & $\begin{array}{l}85-01 \\
87-01 \\
91-01 \\
95-01\end{array}$ & $\begin{array}{l}1985-1987 \\
1987-1991 \\
1991-1995 \\
1996-2000\end{array}$ & $\begin{array}{r}10 \\
8 \\
7 \\
14\end{array}$ & $\begin{array}{l}60.0 \\
50.0 \\
71.4 \\
41.7\end{array}$ & $\begin{array}{l}60.0 \\
62.5 \\
71.4 \\
41.7\end{array}$ & 95 \\
\hline $\begin{array}{l}\text { FRALLE } \\
\text { France }\end{array}$ & $\begin{array}{l}\text { FRALLE } 83 \\
\text { FRALLE } 87 \\
\text { FRALLE } 89 \\
\text { FRALLE } 93\end{array}$ & $\begin{array}{l}1983-1986 \\
1987-1989 \\
1989-1992 \\
1993-1999\end{array}$ & $\begin{array}{l}38 \\
34\end{array}$ & $\begin{array}{l}- \\
-\end{array}$ & $\begin{array}{l}- \\
-\end{array}$ & $\begin{array}{l}96 \\
97\end{array}$ \\
\hline $\begin{array}{l}\text { JCCLSG } \\
\text { Japan }\end{array}$ & $\begin{array}{l}\text { ALL811 } \\
\text { ALL841 }\end{array}$ & $\begin{array}{l}1981-1984 \\
1984-1987\end{array}$ & $\begin{array}{l}9 \\
7\end{array}$ & $\begin{array}{l}33.3 \\
57.1\end{array}$ & $\begin{array}{l}44.4 \\
71.4\end{array}$ & 100 \\
\hline $\begin{array}{l}\text { KYCCSG } \\
\text { Japan }\end{array}$ & $\begin{array}{l}\text { AL851 } \\
\text { ALHR88 }\end{array}$ & $\begin{array}{l}1985-1988 \\
1988-1990\end{array}$ & 7 & - & - & 101 \\
\hline $\begin{array}{l}\text { Ma-Spore } \\
\text { Malaysia, Singapore }\end{array}$ & Ma-Spore ALL 2003 & $2002-2011$ & 21 & 52.4 & - & 102 \\
\hline $\begin{array}{l}\text { NOPHO } \\
\text { Denmark, Finland, Iceland, } \\
\text { Norway, Sweden }\end{array}$ & $\begin{array}{l}\text { No uniform study. } \\
\text { Retrospective analysis of infants treated by } \\
\text { NOPHO institutions }\end{array}$ & $\begin{array}{l}1981-1986 \\
1986-1991 \\
1992-1998\end{array}$ & $\begin{array}{l}23 \\
27 \\
36\end{array}$ & $\begin{array}{l}39.1 \\
18.5 \\
39.9\end{array}$ & $\begin{array}{l}- \\
- \\
-\end{array}$ & 103 \\
\hline $\begin{array}{l}\text { PETHEMA } \\
\text { Spain }\end{array}$ & PETHEMA ALL-93 & 1993-2002 & 12 & $50.0^{d}$ & - & 104 \\
\hline $\begin{array}{l}\text { PINDA } \\
\text { Chile }\end{array}$ & PINDA 87 & 1987-1992 & 15 & 21 & - & 105 \\
\hline $\begin{array}{l}\text { POG } \\
\text { USA }\end{array}$ & POG 8398 & 1984-1990 & 33 & 17.7 & 36.4 & 19 \\
\hline $\begin{array}{l}\text { SJCRH } \\
\text { St Jude Children's Research } \\
\text { Hospital, USA }\end{array}$ & $\begin{array}{l}\text { Total Therapy Study } 10 \\
\text { Total Therapy Study } 11 \\
\text { Total Therapy Study } 12 \\
\text { Total Therapy Study } 13 \mathrm{~A} \\
\text { Total Therapy Study } 13 \mathrm{~B}\end{array}$ & $\begin{array}{l}1979-1983 \\
1984-1988 \\
1988-1991 \\
1991-1994 \\
1994-1998\end{array}$ & $\begin{array}{r}5 \\
11 \\
8 \\
5 \\
10\end{array}$ & $\begin{array}{l}20^{\mathrm{e}} \\
45.5 \\
25.0 \\
20.0 \\
70.0\end{array}$ & $\begin{array}{l}- \\
63.6 \\
50.0 \\
40.0 \\
70.0\end{array}$ & $\begin{array}{l}106 \\
107\end{array}$ \\
\hline
\end{tabular}




\begin{tabular}{|c|c|c|c|c|c|c|}
\hline $\begin{array}{l}\text { UK CLWP } \\
\text { UK }\end{array}$ & $\begin{array}{l}\text { UKALL VIII } \\
\text { UKALL X }\end{array}$ & $\begin{array}{l}1980-1984 \\
1985-1990\end{array}$ & $\begin{array}{l}20 \\
26\end{array}$ & $\begin{array}{l}30.0 \\
26.9\end{array}$ & - & 110 \\
\hline \multicolumn{7}{|c|}{ 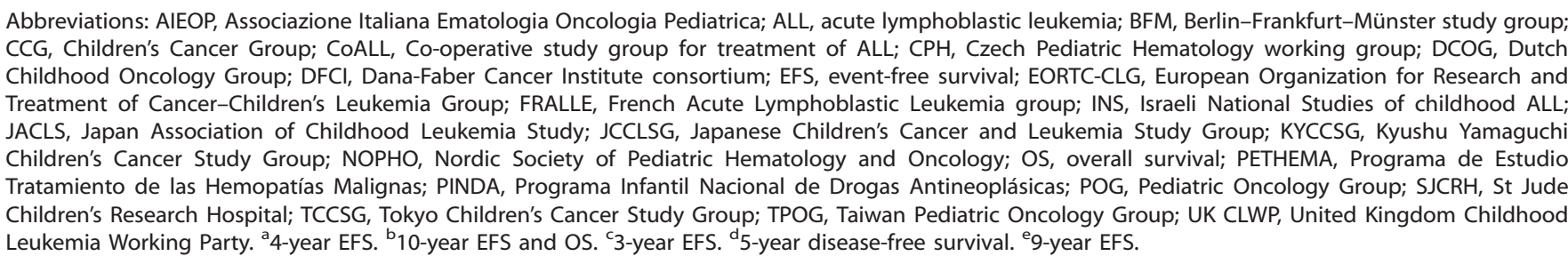 } \\
\hline
\end{tabular}

\section{THE PRESENT: INFANT-SPECIFIC COLLABORATIVE GROUP PROTOCOLS}

Currently, there are three large collaborative groups conducting infant ALL-specific clinical trials-the Children's Oncology Group (COG), the Japanese Pediatric Leukemia/Lymphoma Study Group (JPLSG) and the Interfant Study Group. Their trials and outcomes are described below and summarized in Figure 1 and Table 2.

\section{Children's Oncology Group}

Several US pediatric cooperative trial groups merged in the year 2000 to form the COG. Those groups relevant to the study of childhood leukemia included the Children's Cancer Group (CCG) and the Pediatric Oncology Group (POG), who were the first cooperative groups to conduct clinical trials specific for infant ALL.

\section{CCG trials}

The first infant-specific CCG trials were based on a preceding pilot study for patients with poor prognosis ALL, CCG-192P, that enrolled 27 infants from 1982 to 1984 . This pilot followed a retrospective review of 115 infants treated on preceding noninfant-specific protocols between 1972 and 1982 that revealed a dismal 4-year EFS (23\%) because of disease recurrence rather than excessive toxicity. ${ }^{12}$ The premise of CCG-192P was intensification of multiagent chemotherapy, administered in three phases using weight-based dosages, to prolong remission and ultimately survival, with delayed central nervous system (CNS) prophylaxis of 1800 cGy cranial radiation until patients were $\geqslant 1$ year of age. ${ }^{13}$ Complete remission (CR) following induction was achieved in $92.6 \%$ and no differences in toxicity were observed compared with older children on the same protocol. There was a $36 \%$ 4-year EFS with four CNS relapses, all of whom had received cranial irradiation. Univariate analysis revealed a more favorable outcome for infants with a white blood cell (WBC) count $<50 \times 10^{3} / \mu \mathrm{l}$ and age $>6$ months at diagnosis. ${ }^{13}$

CCG-107 enrolled 98 evaluable infants between 1984 and 1988 and CCG-1883 enrolled 135 evaluable infants between 1989 and 1993. Both studies intensified systemic chemotherapy, administered in five phases with dosages calculated on body surface area, and introduced high-dose methotrexate with intrathecal chemotherapy for CNS prophylaxis. CCG-1883 was further intensified post induction, primarily with the addition of high-dose cytarabine. CR was achieved for $87.8 \%$ on CCG-107 and $94.1 \%$ on CCG-1883. ${ }^{14}$ There was an improvement in 5-year EFS $(37.6 \%$ vs $32.6 \%)$ and OS (50.2\% vs $42.8 \%$ ) when comparing CCG-1883 with CCG-107, ${ }^{15}$ with tolerable toxicities. However, the 5-year disease-free survival (DFS) on CCG-1883 remained low (38.5\%), ${ }^{16}$ with a high overall relapse rate in both studies (CCG-107, 59.2\%; CCG-1883, 55.6\%). Isolated marrow relapse was the most common cause of treatment failure (CCG-107, 35.7\%; CCG-1883, 40.7\%). The majority of first relapses occurred early (within 13 months of diagnosis) and was the primary cause of death. ${ }^{14}$ Nevertheless, the probability of isolated CNS relapse on CCG-1883 was lower (3.0\%) as compared with CCG-107 (8.2\%), ${ }^{15}$ and was similar to a historical control (CCG-160) that used cranial radiotherapy $(5 \%) .{ }^{14}$ This led to the conclusion that compared with cranial radiotherapy, the combination of intrathecal and high-dose systemic therapy represented a superior and effective treatment strategy for prevention of CNS disease, with improved neurodevelopmental outcome. $^{14,17}$ Analysis of combined data from both studies identified several prognostic factors associated with poor outcome, including age $<6$ months at diagnosis, with the most inferior outcome in those $<3$ months, CD10 negativity, failure of morphological remission on day 14 marrow, WBC $>50 \times 10^{9} / \mathrm{l}$ at diagnosis and presence of the $t(4 ; 11) M L L$ rearrangement. ${ }^{14}$

The subsequent study, CCG-1953, aimed to improve the overall poor outcome and reduce the early relapse rate shown in the preceding studies via introduction of early treatment intensification, with dosages based on body surface area and elimination of age-related dose reductions. In addition, the feasibility and outcome of allogeneic hematopoietic stem cell transplantation (HSCT) was examined for MLL-rearranged infants for whom HSCT could be scheduled by 4 months of study entry and a 5-6/6 human leukocyte antigen related or unrelated matched donor was available. Overall, 115 infants were enrolled between 1996 and $2000 .^{16}$ As a consequence of excessive infectious induction toxicity, the daunorubicin dosage during induction was modified, calculated on weight and age at diagnosis, and for infants $\leqslant 90$ days of age at diagnosis, daily short rather than continuous infusion was implemented. CR was achieved in $82.5 \%$ of the infants. ${ }^{16}$ Compared with CCG-1883, there was an improved 5-year EFS $(43.2 \%)^{15}$ and DFS (49.2\%), ${ }^{16}$ but slightly lower 5-year OS $(46.8 \%) .{ }^{15}$ The improvements were especially marked when comparing 5 -year EFS (41.7\% vs $9.5 \%)$ and DFS (56.3\% vs $11.1 \%)$ for infants younger than 90 days of age at diagnosis. There was a significant difference in 5-year EFS between MLL-rearranged 


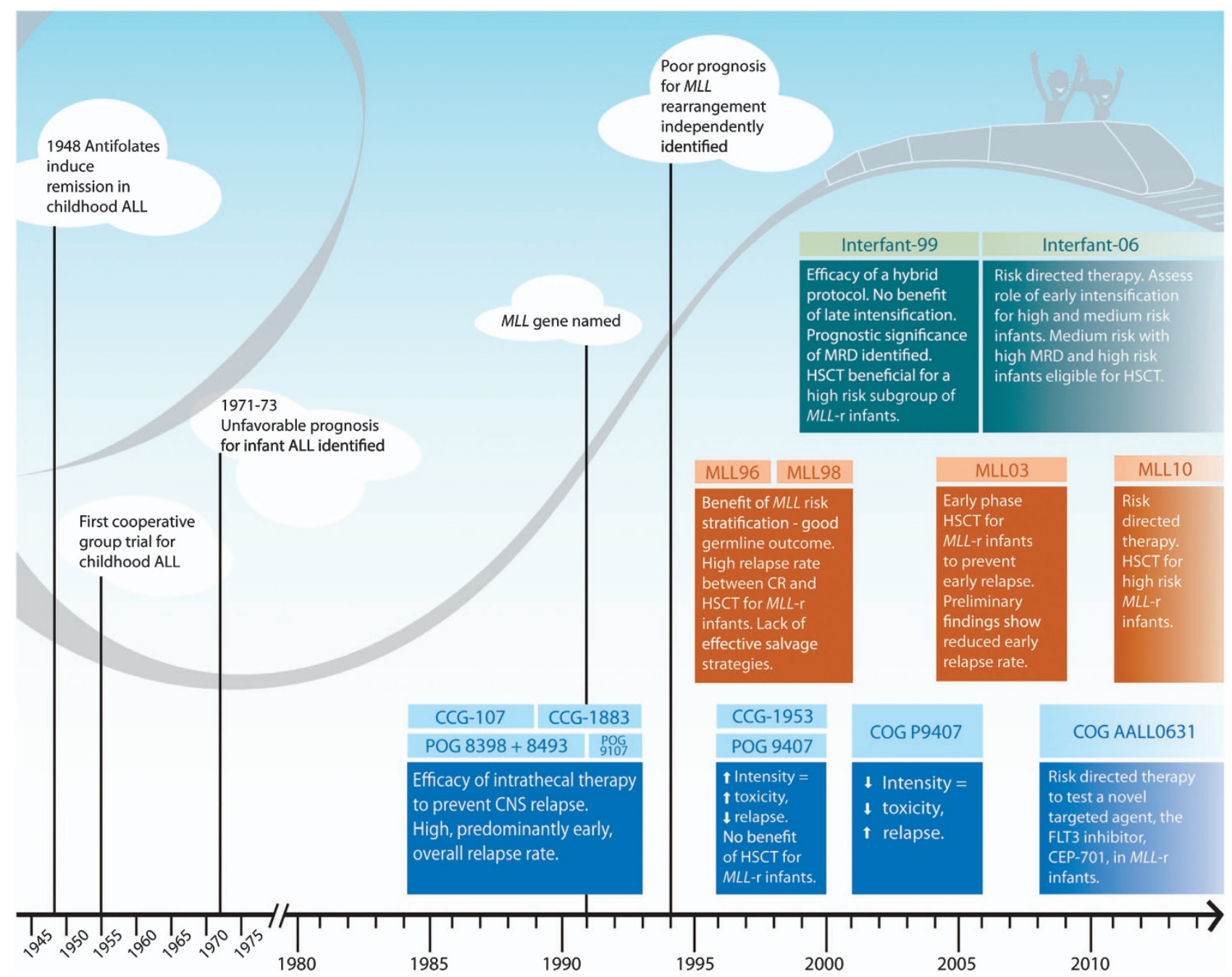

Figure 1. The roller coaster journey of infant ALL.

(33.6\%) and $M L L$-nonrearranged cases (60.3\%) when prognostic factors were considered individually; however, CD10 negativity was the only independent adverse prognostic factor identified. ${ }^{16}$ The key finding of CCG-1953 was that despite fewer relapses $(20.9 \%$ vs $55.6 \%)$, no isolated CNS relapses, ${ }^{15}$ and relapses occurring later compared with CCG-1883, ${ }^{16}$ the remission induction rate was inferior because of early, predominantly infectious, toxicity. ${ }^{18}$

\section{POG trials}

The first infant-specific study, POG 8493, enrolled 84 evaluable infants between 1984 and 1990, with the aim of intensifying therapy using pulsed weight-based doses of cyclophosphamide, vincristine, cytarabine and prednisone (COAP) and teniposide and cytarabine. Despite a CR rate of $89.3 \%,{ }^{19}$ the 5 -year EFS $(25.0 \%)$ and OS (31.6\%) were poor, with adverse prognosis on univariate analysis for age $<9$ months at diagnosis. ${ }^{20}$ POG 8493 ran concurrently with the noninfant-specific POG 8398 pilot study that enrolled 33 evaluable infants. POG 8398 was designed to address early relapse with intensive early consolidation and prevent drug resistance by using rotating drug pairs during this phase. Drug pairs selected included intermediate-dose methotrexate and 6-mercaptopurine, daunorubicin and cytarabine, and teniposide and cytarabine. ${ }^{21} \mathrm{CR}$ was achieved in $93.9 \%$, but 5 -year EFS (17.7\%) and OS (36.4\%) remained poor. ${ }^{19}$
POG 9107 further evaluated postinduction rotating cycles of intensive, weight-based dosing, combination chemotherapy comprising high-dose cytarabine and daunorubicin, intravenous 6-mercaptopurine and methotrexate, etoposide and cytarabine, and COAP with the aim to reduce bone marrow relapse rate with early intensification. There were 47 evaluable infants enrolled between 1991 and 1993, with CR achieved in 89.4\% and an improved 5-year EFS (31.9\%) and OS (40.2\%). Triple intrathecal therapy was used as CNS prophylaxis for all three studies with a low cumulative incidence of isolated CNS relapse on POG 8398/ $8493 / 9107$ of $3.4 \%$ at 10 years. However, there was a high overall relapse rate $(59.8 \%)$, with marrow relapse being the primary cause of treatment failure. ${ }^{19}$ When analyzed in combination, WBC $>50 \times 10^{3} / \mu$ l at diagnosis was identified as the only independent prognostic variable predictive of adverse outcome, with presence of the $t(4 ; 11) \quad M L L$ rearrangement tending to predict poorer outcome. $^{19}$

POG 9407 delivered shortened (46 weeks) intensified therapy, with dosages based on body surface area, using two high-dose methotrexate courses followed by one cyclophosphamide/etoposide course during induction and later as reintensification, with the aim of improving outcome by decreasing early relapse. HSCT was permitted for MLL-rearranged infants following completion of reinduction. Cohort 1 enrolled 16 infants between 1996 and 1997, with daunorubicin administered during induction and reinduction as a body surface area-based $48-\mathrm{h}$ continuous infusion. Due to 
Table 2. Summary of results for infant-specific collaborative group ALL protocols

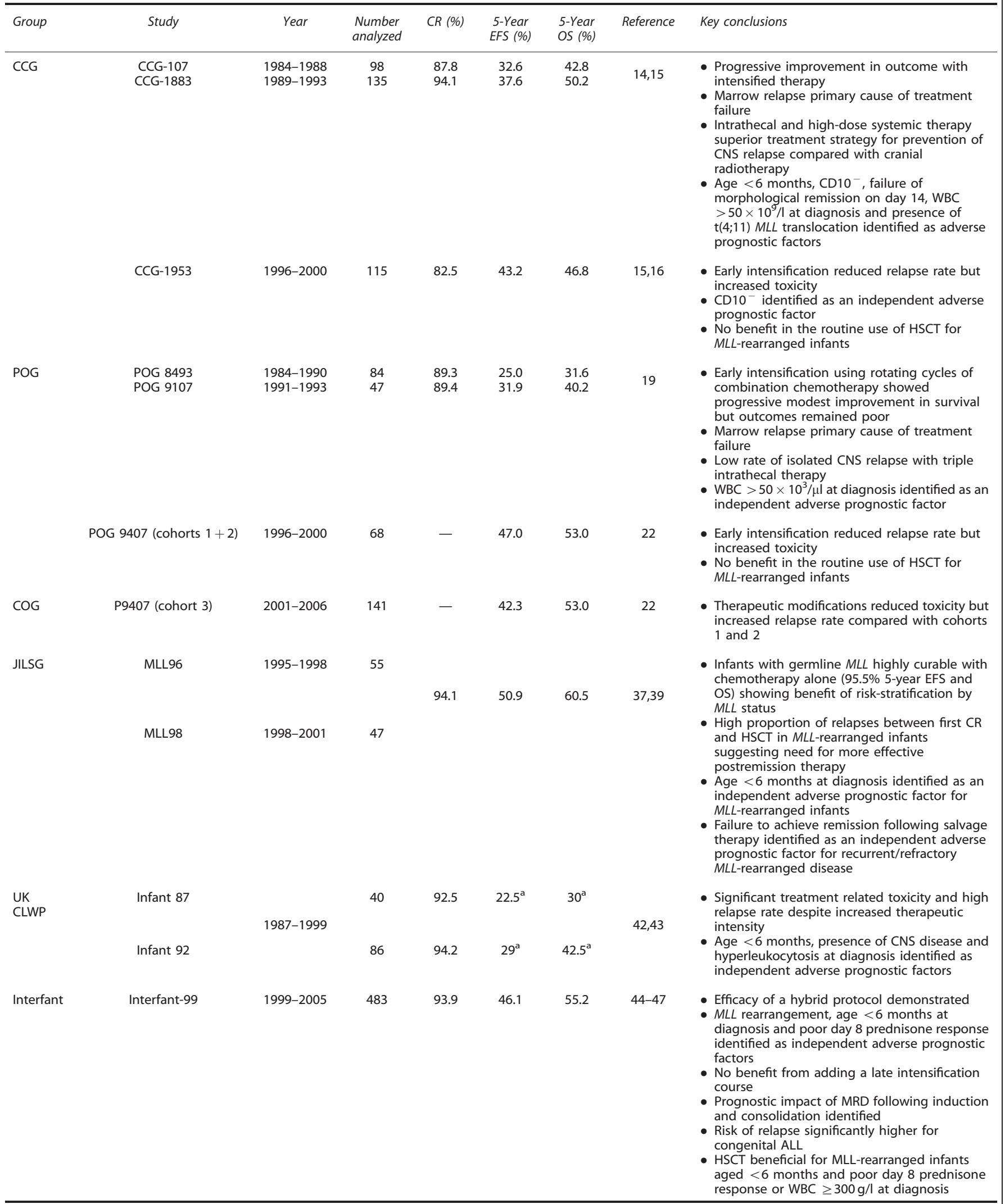

Abbreviations: ALL, acute lymphoblastic leukemia; CCG, Children's Cancer Group; CNS, central nervous system; COG, Children's Oncology Group; CR, complete remission; EFS, event-free survival; $\mathrm{HSCT}$, hematopoietic stem cell transplantation; JLSG, Japan Infant Leukemia Study Group; MLL, mixed lineage leukemia; MRD, minimal residual disease; OS, overall survival; POG, Pediatric Oncology Group; UK CLWP, United Kingdom Childhood Leukemia Working Party; WBC, white blood cell count. ${ }^{\mathrm{a}} 6$-year EFS and OS; UK CLWP studies included 9 patients between 12 and 18 months of age with biological features of infant ALL. 
excessive toxicity, the same amendments for CCG-1953 regarding daunorubicin during induction were made for cohort 2 that enrolled 52 infants between 1997 and 2000. For the 68 infants, the 5 -year EFS and OS were $47 \%$ and $53 \%$, respectively. ${ }^{22}$ However, there was a high early death rate $(25 \%)$, defined as within 90 days of enrollment, particularly among infants $\leqslant 90$ days of age $(58.8 \%$ vs $13.7 \%)$, with the majority of deaths attributable to infection. ${ }^{22}$

A total of 53 patients underwent HSCT on the parallel CCG-1953 and POG 9407 studies (Table 3). HSCT was the preferred treatment for infants with MLL rearrangements on CCG-1953, whereas on POG 9407 transplantation was an investigator option. HSCT according to the protocol-specified conditioning, consisting of cytarabine, cyclophosphamide, methylprednisolone and total body irradiation, was undertaken in 25 cases, whereas the remainder followed nonprotocol-specified regimens. Median time to transplant from first CR was 4.7 months (range 3-13). The 5-year EFS (48.8\%) and OS (53.1\%) were comparable to a control group of $47 \mathrm{MLL}$-rearranged infants who were enrolled on study but did not receive HSCT (5-year EFS 48.7\%, 5-year OS 59.4\%), suggesting no benefit in the routine use of HSCT for infants with $M L L$-rearranged ALL. $^{23}$

\section{COG trials}

The COG continued the premise of POG 9407, enrolling 141 infants on P9407 cohort 3 from 2001 to 2006. Modifications aimed to reduce toxicity and included substitution and relative dose reduction of steroid during induction, reinduction and continuation (dexamethasone $10 \mathrm{mg} / \mathrm{m}^{2}$ per day replaced with prednisone $40 \mathrm{mg} / \mathrm{m}^{2}$ per day) and substitution of the continuous with daily short daunorubicin infusions during induction and reinduction for all infants. In addition, extensive supportive care recommendations were provided. Compared with the preceding cohorts, a reduction in the early death rate $(5.7 \%)$ for all age groups was offset by a significantly increased overall relapse rate $(37.6 \%$ vs $17.6 \%),{ }^{22}$ resulting in unchanged 5 -year EFS $(42.3 \%)$ and OS (53\%).

AALL01P1, a limited institution pilot study, opened in 2002. It aimed to demonstrate the feasibility of an augmented intensive regimen with a dexamethasone-based induction and augmented consolidation followed by a modified augmented Berlin-Frankfurt-Münster (BFM) regimen for infants who did not undergo HSCT. However, this study closed in 2003 because of poor accrual.

The current COG trial, AALL0631 (http://clinicaltrials.gov/ct2/ show/NCT00557193), opened in 2008 and incorporates riskdirected therapy according to significant prognostic factors identified from combined analysis of the three 9407 cohorts.
Infants are classified as standard risk ( $M L L$-nonrearranged), intermediate risk ( $M L L$-rearranged, $\geqslant 90$ days at diagnosis) or high risk (MLL-rearranged, $<90$ days at diagnosis). Initially, therapy was a modified COG P9407-based induction. As a result of excessive toxicity, the study was amended for all infants to receive an Interfant-99-based induction, modified to eliminate the steroid taper, reduce all nonintrathecal chemotherapy doses by $25 \%$ for infants $<7$ days old at diagnosis and introduce enhanced supportive care guidelines. ${ }^{24,25}$ The postinduction chemotherapy backbone is based on P9407 with an extended continuation to deliver therapy for a total of 2 years to all patients, with the aim to reduce late relapse seen on P9407. More intensive postinduction chemotherapy for $M L L$-rearranged infants has the goal of reducing the high proportion of relapses reported during continuation for MLL-rearranged infants on P9407.

AALL0631 is the first collaborative group trial to incorporate a novel targeted therapy for infant ALL. Following a successful drug safety and activity phase, ${ }^{26,27}$ MLL-rearranged infants were randomized to receive the highly selective small molecule Fms-like tyrosine kinase 3 (FLT3) inhibitor, CEP-701. High FLT3 protein levels are expressed in the leukemic blasts of infants with $M L L$-rearranged $\mathrm{ALL}^{28}$ even in the absence of $F L T 3$ activating mutations, which occur in $<20 \%$ of infants with MLL-rearranged ALL. ${ }^{29-31}$ Due to drug supply limitations, a subsequent amendment ensures that al newly enrolled MLL-rearranged infants receive CEP-701, with a decrease in the overall duration of CEP-701 therapy.

\section{Japanese Pediatric Leukemia/Lymphoma Study Group}

The JPLSG was founded in 2003 and became the single collaborative group unifying Japan in 2010 following complete amalgamation of the Tokyo Children's Cancer Study Group (TCCSG), the Japanese Children's Cancer and Leukemia Study Group (JCCLSG), the Japan Association of Childhood Leukemia Study (JACLS) and the Kyushu Yamaguchi Children's Cancer Study Group (KYCCSG). However, a unified approach for the study of infant leukemia in Japan had commenced before formation of the JPLSG under the guise of the Japan Infant Leukemia Study Group (JILSG).

The JILSG were the first group to study the effectiveness of riskadapted therapy according to the presence or absence of MLL rearrangements, based on this being identified as the most important prognostic factor for infant ALL. ${ }^{9,32-34}$ Two consecutive protocols, MLL96 and MLL98, enrolled 102 infants between 1995 and 2001. ${ }^{35-37}$ MLL-rearranged infants received induction and three courses of postremission intensification followed by HSCT, with protocol-specified conditioning comprising either total body irradiation or busulfan, etoposide and cyclophosphamide, if a 5-6/6 human leukocyte antigen-matched related, 6/6-matched

Table 3. Summary of results for allogeneic HSCT in first CR in clinical trials for infant ALL

\begin{tabular}{|c|c|c|c|c|c|c|c|}
\hline \multirow[t]{2}{*}{ Group } & \multirow[t]{2}{*}{ Study } & \multirow[t]{2}{*}{ Year } & \multirow{2}{*}{$\begin{array}{l}\text { Number with } \\
\text { HSCT in first } C R\end{array}$} & \multicolumn{3}{|c|}{ Outcome post HSCT } & \multirow[t]{2}{*}{ Reference } \\
\hline & & & & Continued first $C R$ & Death in $C R$ & Relapse & \\
\hline CCG & CCG-1883 & 1989-1993 & 12 & 2 & 5 & 5 & 14 \\
\hline UK CLWP & Infant $87 / 92$ & 1987-1999 & 15 & 5 & 3 & 7 & 42,43 \\
\hline AIEOP & AIEOP-ALL 91/95 & $1991-2000$ & 6 & 3 & 3 & 0 & 111 \\
\hline JILSG & MLL96/98 & $1995-2001$ & 47 & 27 & 8 & 12 & 37 \\
\hline COG & CCG-1953/POG 9407 & $1996-2000$ & 53 & 27 & 17 & 9 & 23 \\
\hline \multirow[t]{2}{*}{ Interfant } & Interfant-99 & 1999-2005 & 37 & 21 & 2 & 14 & 45 \\
\hline & Total & $1987-2005$ & 170 & 85 & 38 & 47 & \\
\hline
\end{tabular}

Abbreviations: AIEOP, Associazione Italiana Ematologia Oncologia Pediatrica; ALL, acute lymphoblastic leukemia; CCG, Children's Cancer Group; COG, Children's Oncology Group; CR, complete remission; HSCT, hematopoietic stem cell transplantation; JILSG, Japan Infant Leukemia Study Group; UK CLWP, United Kingdom Childhood Leukemia Working Party. 
unrelated or 4-6/6-matched cord blood donor was available. Infants with germline $M L L$ received intensive chemotherapy administered over 83-85 weeks. Aside from vincristine, drug dosages were calculated on body surface area for MLL98 as compared with weight for MLL96. Despite resulting in a 1.2- to 2-fold increase in dosage for MLL98, this was not associated with improved outcome. ${ }^{37}$

For all 102 infants, CR was achieved in $94.1 \%$, with 5-year EFS and OS of $50.9 \%$ and $60.5 \%$, respectively. ${ }^{37}$ These studies were fundamental in demonstrating the benefit of risk-adapted therapy according to MLL status, with outcomes significantly better for infants with germline $M L L$ compared to those with $M L L$-rearranged disease. There were 22 infants with germline $M L L$ who were highly curable, all achieving $\mathrm{CR}$, with 5-year EFS and OS of $95.5 \%{ }^{38}$ In contrast, although the 80 MLL-rearranged infants achieved a similar CR rate $(92.5 \%)$, the 5 -year EFS and OS were $38.6 \%$ and $50.8 \%$, respectively. Of the $74 \mathrm{MLL}$-rearranged infants who achieved $C R, 53$ remained in $C R$ during the postremission phase, with 47 undergoing allogeneic HSCT (Table 3), 2 receiving high-dose chemotherapy and autologous stem cell rescue and 4 with no suitable donor who remained in CR with chemotherapy alone. ${ }^{37}$ The median time to transplant from first remission was 4 months (range 0-9).

Relapse occurred in 34 MLL-rearranged infants, with isolated bone marrow relapse occurring in 30 and 2 isolated CNS relapses. Another key conclusion from these studies was the need for more effective postremission therapy, as a high proportion of relapse $(61.7 \%, n=21 / 34)$ occurred before HSCT. ${ }^{39}$ Age $<6$ months was the only independent prognostic factor associated with inferior outcome for MLL-rearranged infants (5-year EFS 27.8\% <6 months vs $52.9 \% \geqslant 6$ months) with CNS disease at diagnosis identified on univariate analysis. ${ }^{37}$ Compared with the germline group, univariate analysis demonstrated that $M L L$-rearranged infants were significantly younger, had higher WBC counts, increased frequency of CNS disease and CD10 negativity at diagnosis. ${ }^{37}$

MLL03 built on findings of the preceding studies with the aim of early phase ( $\leqslant 4$ months after first CR) HSCT to prevent early relapse for $M L L$-rearranged infants. The study recruited 63 infants between 2004 and 2009. Therapy consisted of a 7-day prednisolone prophase followed by induction that included dexamethasone, vincristine, doxorubicin, cyclophosphamide, cytarabine, etoposide and triple intrathecal therapy, followed by two intensification courses including high-dose methotrexate and high-dose cytarabine. If $C R$ was achieved and $a \geqslant 5 / 6$-matched related or $\geqslant 4 / 6$-matched unrelated cord blood donor was available, HSCT was performed using a busulphan, etoposide and cyclophosphamide protocol-specified conditioning. Preliminary data have shown 18 -month EFS and OS of $54.5 \%$ and $80.8 \%$, respectively, ${ }^{40}$ with a reduced early relapse rate, occurring in 3 patients before HSCT compared with 21 patients following HSCT. ${ }^{41}$

The aim of the current JPLSG study, MLL10 (https://upload.umin. ac.jp/cgi-open-bin/ctr/ctr.cgi?function=brows\&action=brows\&type = summary\&recptno $=$ R000005714\&language $=E$ ), which opened in 2011 , is to evaluate the efficacy and safety of risk-directed therapy using a new stratification system. MLL germline infants are classified low risk and treated with the MLL96/98 chemotherapy backbone. MLL-rearranged infants $\geqslant 180$ days of age with no CNS disease are intermediate risk and treated with intensive combination therapy without HSCT in first CR. MLL-rearranged infants $<180$ days of age or with CNS disease are deemed high risk and treated with intensive combination therapy with HSCT in first CR.

\section{Interfant Study Group}

The Interfant Study Group is a large international collaborative dedicated to infant ALL research, with representation from the Dutch Childhood Oncology Group (DCOG), BFM study group,
Associazione Italiana Ematologia Oncologia Pediatrica (AIEOP), Australian and New Zealand Children's Hematology/Oncology Group (ANZCHOG), European Organization for Research and Treatment of Cancer-Children's Leukemia Group (EORTC-CLG), Co-operative study group for treatment of ALL (CoALL), Czech Pediatric Hematology working group $(\mathrm{CPH})$, French Acute Lymphoblastic Leukemia group (FRALLE), Nordic Society of Pediatric Hematology and Oncology (NOPHO), Programa Infantil Nacional de Drogas Antineoplásicas (PINDA), Polish Pediatric Leukemia and Lymphoma Study Group (PPLLSG), United Kingdom Children's Cancer and Leukemia Group (CCLG), St Jude Children's Research Hospital, Dana-Faber Cancer Institute consortium, MD Anderson Cancer Center and centers from Seattle, Argentina and Hong Kong.

Before formation of the Interfant Study Group, the UK Medical Research Council Childhood Leukemia Working Party, now operating as the CCLG, conducted two infant-specific studies. Infant 87 was a pilot study designed to increase the intensity of therapy from the preceding risk-adapted UKALL trials, with inclusion of drug combinations with recognized actions against acute myeloid leukemia and to provide effective CNS-directed therapy without cranial irradiation. Drug dosages were calculated on body surface area. A four-drug induction was followed by 5 days of etoposide and cytarabine, with three subsequent high-dose methotrexate infusions. Further intensification was given with mitoxantrone and cytarabine followed by a further reinduction course. ${ }^{42}$ Subsequent therapy was not standardized and options included HSCT for infants with a matched sibling donor, high-dose chemotherapy and autologous stem cell rescue or standard continuation. The study enrolled 40 infants with CR achieved in $92.5 \%$. Despite increased intensity of therapy, there was no improvement in survival (6-year EFS, 22.5\%; 6-year OS, 30\%) compared with infants enrolled on the preceding risk-adapted UKALL protocols, with a high number of toxic deaths especially following the 5-day course of etoposide and cytarabine. There was a high overall relapse rate of $47.5 \%$, with isolated marrow relapse accounting for $37.5 \%$ and isolated CNS relapse $5 \% .{ }^{43}$ Outcome for 8 infants who underwent high-dose chemotherapy followed by autologous stem cell rescue was not encouraging, with 5 suffering bone marrow relapse.

The subsequent study, Infant 92, enrolled 86 patients between 1992 and 1999. As a result of excessive toxicity on Infant 87, modifications included a reduction in the duration of etoposide and cytarabine from 5 to 4 days, interim maintenance rather than reinduction at week 20, followed by an 8-week delayed intensification before continuation. ${ }^{43}$ HSCT was permitted for MLL-rearranged infants with a matched donor. CR was achieved in $94.2 \%$ with a modest improvement in 6-year EFS (29\%) and OS (42.5\%). However, there remained a high overall relapse rate $(55.8 \%)$, and despite a slight reduction in the isolated marrow relapse rate $(32.6 \%)$, there was an increase in the isolated CNS relapse rate $(11.6 \%) .{ }^{43}$ There was no difference in EFS for the 12 patients who underwent HSCT in first remission compared with those who had chemotherapy alone. CNS disease, age $<6$ months and higher WBC count at diagnosis were independently associated with an adverse prognosis following combined analysis from both studies. ${ }^{43}$

The first trial of the Interfant Study Group, Interfant-99, enrolled 483 infants between 1999 and 2005. ${ }^{44,45}$ This study continued with a hybrid treatment schedule comprising elements used to treat both ALL and acute myeloid leukemia, while minimizing the use of anthracyclines and alkylating agents. Based on results of infants enrolled onto preceding BFM studies, ${ }^{11}$ all infants received a 7-day prednisone prophase with stratification into standard- and high-risk groups determined by day 8 peripheral blood blast count $(</ \geqslant 1000$ cells/ $\mu$ l, respectively). High-risk infants had the option of receiving HSCT at the end of reinduction if a suitable donor was 
available, otherwise they were scheduled to have cytarabine and etoposide added to their standard maintenance. The protocol administered age-based dosing calculated on body surface area. CR was achieved in $93.9 \%$ of 474 evaluable infants at the end of induction. ${ }^{44}$ The 5 -year EFS and OS were $46.1 \%$ and $55.2 \%$, respectively. ${ }^{45} \mathrm{MLL}$ germline infants had the best outcome, with 5 -year EFS of $74.0 \%$. Overall relapse rate was $34.4 \%$, with isolated marrow relapse accounting for $25.7 \%$ and isolated CNS relapse $2.5 \%,{ }^{44}$ with significantly higher risk of relapse identified for congenital leukemia. ${ }^{46}$ Independent prognostic factors associated with an inferior outcome included presence of an MLL rearrangement, age $<6$ months at diagnosis and poor prednisone response at day 8 , with CD10 negativity and WBC $\geqslant 300 \times 10^{9} / \mathrm{l}$ at diagnosis also identified on univariate analysis. A higher proportion of infants $<6$ months of age at diagnosis were MLL rearranged, with the majority of $t(4 ; 11)$ and $t(11 ; 19)$ translocations occurring in this group, whereas the majority of $t(9 ; 11)$ translocations occurred in infants aged 6-12 months at diagnosis. $^{44}$

Interfant-99 also assessed the efficacy of late intensification comprising vincristine, 6-mercaptopurine, high-dose methotrexate, high-dose cytarabine, asparaginase and additional triple intrathecal therapy, with 191 eligible infants randomized to receive this course between reinduction and maintenance. There was no difference in outcome, with substantial toxicity associated with this additional intensification phase. ${ }^{44}$

The prognostic significance of minimal residual disease (MRD), analyzed by real-time quantitative PCR analysis of rearranged immunoglobulin/T-cell receptor genes and/or MLL genes, was tested in 99 infants following induction and consolidation. High MRD was significantly associated with lower DFS. All infants who had MRD $\geqslant 10^{-4}$ following consolidation relapsed, whereas the lowest relapse rate $(13 \%)$ was seen in patients who had MRD $<10^{-4}$ following induction and consolidation. All MLL germline infants had MRD $<10^{-4}$ following consolidation and remained in remission. $^{47}$

There were $37 \mathrm{MLL}$-rearranged infants who underwent HSCT at a median time of 5 months (range 2-9) from first CR (Table 3). A preparative regimen of busulfan, etoposide and cyclophosphamide was advised, but donor selection, conditioning and graft versus host disease prophylaxis and treatment were not mandated. When compared with $240 \mathrm{MLL}$-rearranged infants who received chemotherapy alone after first $C R$, there was significantly improved DFS and OS for a subgroup of high-risk MLL-rearranged infants with unfavorable prognostic features, including age $<6$ months and either poor day 8 prednisone response or WBC $\geqslant 300 \mathrm{~g} / \mathrm{l}$ at diagnosis, although this subgroup also had a high early failure rate, with a third having an event before the median time to transplantation. ${ }^{45}$

The current study, Interfant-06 (http://clinicaltrials.gov/show/ NCT00550992) commenced enrollment in 2006 and, based on results of Interfant-99, stratifies infants into low risk (MLL germline), high risk (MLL-rearranged and age $<6$ months and WBC $\geqslant 300 \times 10^{9} / \mathrm{l}$ at diagnosis and/or poor day 8 prednisone response) and medium risk (all other cases). The study aims to assess early intensification to improve outcome and prevent early relapse, as opposed to the late intensification considered for Interfant-99. High- and medium-risk infants are randomized to two 'acute myeloid leukemia' induction blocks (cytarabine, daunorubicin and etoposide; cytarabine, mitoxantrone and etoposide) versus the control arm, also specified for all low-risk infants, comprising BFM IB (6-mercaptopurine, cytarabine, cyclophosphamide) following induction, with medium-risk infants with MRD $\geqslant 10^{-4}$ following consolidation and all high-risk infants also eligible for HSCT after consolidation. The remainder of therapy is similar to Interfant-99, with the main modifications including intensification of asparaginase therapy and removal of dexamethasone and vincristine during maintenance.
Summary of outcomes from the infant-specific protocols A wealth of information has been gleaned from the infant-specific clinical trials. Concise outcomes for each study are summarized in Table 2, including a number of landmark findings that underpin our current therapeutic approaches for infant ALL (Figure 1). An essential early discovery, with subsequent universal adaptation by each of the study groups, was the use of intrathecal and high-dose systemic therapy, with the elimination of cranial radiotherapy, for prevention of CNS disease with improved neurodevelopmental outcome. Second, nowhere has the balance between treatment efficacy and toxicity been better demonstrated than for infant ALL, where the infant-specific trials have varied in therapeutic intensity, with recent survival outcomes unchanged due to the equilibrium between relapse and toxicity (Figure 1). Analysis of outcomes drawn from this conclusion has led to beneficial chemotherapeutic features identified from prior trials being uniformly incorporated into contemporary studies. These include the adoption of an Interfant-99-based induction given its satisfactory CR rate and acceptable toxicity profile, the necessity of an extended continuation to prevent late relapse and mandating enhanced aggressive supportive care measures to minimize risk of infection. Current published data, however, do not reveal a superior chemotherapeutic backbone on which to base future trials for MLLrearranged infants, with similar EFS across each of the collaborative groups (CCG-1953: 33.6\%, 5-year EFS ${ }^{16}$; JPLSG MLL96/98: 38.6\%, 5-year $\mathrm{EFS}^{37}$; Interfant-99: 36.8\%, 4-year $\mathrm{EFS}^{45}$ ), although additional insight may be provided following results of the contemporary treatment protocols. Finally, the universal prospective identification of independent adverse prognostic factors, including presence of an MLL-rearrangement and young age, has resulted in such variables forming a standard component of risk stratification in each of the current trials. It is these landmark outcomes that provide the foundation for the next generation of clinical trials for infant ALL.

\section{THE FUTURE: THE NEXT GENERATION OF TRIALS FOR INFANT ALL}

Substantial therapeutic advances have been made for infant ALL since the first pediatric cooperative group ALL trials were conceived. Key events include the identification of inferior outcome for infants compared with older children, discovery of prognostic features within infant ALL, in particular the dismal outcome associated with an $M L L$ rearrangement, formation of the three large collaborative groups dedicated to the study of infant ALL with treatment on infant-specific protocols and incorporation of risk-directed therapy according to prognostic features (Figure 1). Although there has been an increase in survival over time, this is predominantly attributable to the improved outcome of infants with germline $M L L$. Survival for $M L L$-rearranged infants remains significantly inferior to older children and we are approaching the limit for which conventional chemotherapeutic agents can be intensified to optimize the balance between relapse and toxicity. Globalization combined with the recent explosion of molecular data have provided the armamentarium for the next generation of clinical trials for infant ALL. A number of key issues require addressing in future trials to ultimately translate into improved outcome.

\section{The role of HSCT in first complete remission}

Although each of the infant-specific ALL study groups have attempted to prospectively define the role for HSCT in first CR, no clear consensus has been drawn. ${ }^{23,36,37,45}$ Differing conclusions from preceding studies have consequently led to differences between study groups regarding the role of HSCT within current infant-specific protocols. The combined prospective study data do not appear to demonstrate additional benefit for HSCT in first CR 
(Table 3); however, these data are reflective of a heterogeneous infant ALL population treated with diverse HSCT protocols over different time periods. The absence of randomized controlled study designs to compare HSCT with chemotherapy alone further adds to the limitations of the available prospective data. A number of retrospective reports have mirrored such findings, demonstrating both advantage ${ }^{48-51}$ and no clear benefit ${ }^{52-55}$ of HSCT in first CR for infant ALL. Such conflicting results may be attributable to the small number of patients who have undergone HSCT within each study and the marked variability of transplant protocols used. Although it is accepted that HSCT should not be administered for $M L L$ germline cases in first CR, the subgroup of MLL-rearranged infants for whom HSCT in first CR could be definitively performed, the optimal timing at which HSCT should be undertaken and the most suitable transplant protocol remain to be defined. However, on the basis of this review, we conclude that currently there is insufficient evidence to support the use of HSCT in first CR for infant ALL.

Identification of novel prognostic markers and adaptation of innovative therapies

The $M L L$ gene was named in $1991,{ }^{56,57}$ and considerable research has subsequently been dedicated to the molecular mechanisms underlying oncogenesis for $M L L$-rearranged infant leukemia. The explosion of scientific discovery associated with recent technological advances has enabled identification of additional molecular prognostic markers, novel targets and development of innovative therapies. Molecular markers recently identified as independent predictors of poor prognosis for MLL-rearranged infant ALL include RAS mutations, ${ }^{58}$ low FAS expression, ${ }^{59}$ absence of HOXA expression ${ }^{60}$ and using gene expression profiling-based gene classifiers. ${ }^{61}$ The challenge underlying the wealth of prognostic characterization, however, is to identify the most appropriate candidates for integration into future clinical trials.

The FLT3 inhibitor, CEP-701, is the first novel agent investigated in a large collaborative clinical trial for MLL-rearranged infant ALL. There are numerous other drug candidates tested in infantspecific preclinical models with translational potential. These include drugs targeting the aberrant epigenetic profile identified in $M L L$-rearranged infant ALL. An overall global hypermethylated state has been identified for $t(4 ; 11), t(11 ; 19)$ and $t(9 ; 11)$ rearranged infants ${ }^{62}$ and promoter CpG island hypermethylation in $t(4 ; 11)$ and $t(11 ; 19)$ rearranged infants with subsequent silencing of transcriptional genes and microRNAs. ${ }^{63-65}$ Several studies have demonstrated in vitro efficacy of demethylating agents, such as decitabine, zebularine and 5-azacitidine. ${ }^{62-66}$ In addition, hypomethylation has been demonstrated in a subset of highly expressed proto-oncogenes in $t(4 ; 11)$ rearranged infants with in vitro response to histone deacetylase inhibitors. ${ }^{67}$

Overexpression of members of the antiapoptotic B-cell lymphoma 2 family have been identified in MLL-rearranged infant ALL. ${ }^{68,69}$ B-cell lymphoma 2 inhibition provides a promising therapeutic strategy with in vitro activity demonstrated for obatoclax, ${ }^{70}$ ABT-737, ${ }^{71}$ and G3139. ${ }^{68}$ Another approach includes targeting the constituently activated Janus kinase/signal transducer and activator of transcription signaling pathway identified in CD10-negative infant ALL, with effective apoptosis of cells in vitro using the Janus kinase 3 inhibitor, WHI-P131 and the pan-Janus kinase inhibitor, AG-490. ${ }^{72}$ In vitro inhibition of the phosphatidylinositide 3-kinase/AKT/mammalian target of rapamycin signaling pathway has identified compounds such as thioridazine worthy of further investigation. ${ }^{73}$ In vivo studies include potent single agent activity of the antibody-drug conjugate, SAR3419, in infant-MLL xenografts expressing CD19, ${ }^{74}$ and in vivo efficacy of the p53-MDM2 inhibitor, RG7112, as a single agent and in combination with an induction-type chemotherapy regimen. $^{75}$
An alternative approach to targeted therapy is to use novel or existing agents to enhance the efficacy of conventional therapeutics. This includes overcoming glucocorticoid resistance using Src kinase inhibitors ${ }^{76,77}$ and phosphatidylinositide 3-kinase inhibitors $^{78}$ in vitro and enhancing the efficacy of CEP-701 via CXCR4 inhibition using plerixafor in vivo. ${ }^{79}$

In addition, there are numerous exciting new candidates exhibiting potency in noninfant ALL-specific MLL-rearranged preclinical studies such as inhibitors of DOT $1 \mathrm{~L},{ }^{80,81}$ menin $^{82}$ and AMP-activated protein kinase ${ }^{83}$ that remain primed for testing in infant ALL-specific preclinical models.

However, incorporating novel agents into clinical trials is fraught with translational barriers. A number of strategies are being addressed to overcome the classic translational roadblocks, ${ }^{84}$ and it is imperative to have commitment from stakeholders once an agent is considered for a clinical trial. With recent advances, the future will yield a multitude of potential candidates for testing in the setting of a clinical trial. Although the rarity of infant ALL precludes investigation of every suitable drug, the use of adaptive 'pick a winner' trial designs or assessment of novel agents within the relapsed/refractory disease setting may enable differentiation of the most suitable agent for further investigation.

\section{Treatment strategies for relapsed/refractory disease}

Treatment of relapsed/refractory infant ALL constitutes a significant challenge as there is no defined therapy. The absence of an infant-specific relapse study has led to treatment on relapsed childhood ALL protocols or individualized therapy at the discretion of the treating institution. The lack of a uniform centralized approach is reflected by the paucity of outcome measures for relapsed/refractory infant ALL.

The JILSG retrospectively reviewed 39 infants with relapsed $(n=34)$ and refractory $(n=5)$ MLL-rearranged ALL from the MLL96 and MLL98 studies. ${ }^{39}$ These patients underwent a variety of salvage therapies. CR was achieved in $40.5 \%$ and 5 -year OS was $25.6 \%$, with failure to achieve remission following second-line therapy identified as the sole independent prognostic factor, and age $<3$ months and CNS involvement at initial diagnosis associated with higher risk of failure on univariate analysis. ${ }^{39}$ Nine patients received HSCT in second $\mathrm{CR}$, with 5 continuous second remissions, 3 relapses and 1 toxic death. A total of 14 patients received HSCT with active disease, with 2 continuous second remissions, 8 relapse deaths and 4 toxic deaths. One patient who had refractory disease remains in continuous second remission following chemotherapy alone. ${ }^{39}$ The poor outcome for MLL-rearranged infants with induction failure has also been highlighted in a large international retrospective analysis, with 10-year OS of $4 \%$ compared with $65 \%$ for MLL-nonrearranged infants. ${ }^{85}$ The UK CLWP Infant 92 study reported a 6-year OS of $20 \%$ for 48 infants who relapsed. ${ }^{43} \mathrm{~A}$ total of 10 patients received HSCT while in second $\mathrm{CR}$, with 3 continuous second remissions, 3 relapses and 4 HSCT-related deaths; however, the MLL status of the relapsed patients was not specified. A retrospective single-center analysis found salvage possible in a proportion of patients who achieved CR following relapse with the use of HSCT (3-year EFS, 43\%), with dismal outcomes for those receiving HSCT with active disease following relapse (3-year EFS, $6 \% .^{50}$ Outcomes for MLL-rearranged infants, however, were poor in both groups.

In the absence of any defined therapy for relapsed/refractory disease, these limited findings suggest the feasibility of HSCT, provided that CR can be achieved before transplant. It is evident, however, that considerable attention is required for the treatment of relapsed/refractory disease. This may be facilitated through mandatory reporting of such cases to the study groups by the treating institution, establishment of an international registry or a single unified infant-specific trial for relapsed/ refractory disease. 
Late effects in survivors

There is an increasing recognition of late effects in survivors of infant ALL. Cranial radiation was the main risk factor for development of late effects; ${ }^{10,86}$ however, adaptation of high-dose methotrexate and intrathecal chemotherapy as CNS-directed therapy has led to a substantial improvement in neurodevelopmental outcome. ${ }^{17}$ Currently, the main contributory factors for the increasing burden of late effects include the increasing number of survivors with time for late effects to be appreciated, increased intensity of therapy, young age at which therapy is delivered and emergence of late effects as a subspecialty. The long-term sequelae attributable to cranial radiation ${ }^{10,86}$ and $\mathrm{HSCT}^{37,50}$ in survivors of infant ALL have been well documented, but there are limited data available for the remainder. Long-term follow-up of survivors should be encouraged in future clinical trials to further identify and characterize the pattern of long-term morbidity and allow for timely intervention.

\section{CONCLUSION}

Clinical trials for infant ALL have evolved significantly over time, with each stage providing vital contributions to the biological and therapeutic advances that have been achieved. Despite these advances, survival of infants with ALL continues to remain significantly inferior to older children. We are approaching the limit to which conventional chemotherapy can be intensified with acceptable toxicity to minimize relapse. There is a need to identify and incorporate the most promising drug candidates from preclinical studies into the next generation of clinical trials. Integration of novel molecular prognostic markers, the role of HSCT in first remission, treatment strategies for relapsed/refractory disease and monitoring and timely intervention of late effects require addressing in future trials. The heterogeneity and rarity of infant ALL is the major limitation for clinical trials, resulting in slow accrual over long time periods and limiting study power. Global harmonization and maximization of accrual could be achieved through a unified international trial, involving the three major collaborative infant ALL study groups and engaging missing nations that have the ability to partake. ${ }^{87}$ Despite the inherent administrative, legal, drug supply and regulatory difficulties associated with such an approach, feasibility has been demonstrated by a number of global collaborative pediatric cancer trials including the European and American Osteosarcoma Study Group (EURAMOS) trial and the Intergroup trial for B-cell Non-Hodgkin lymphoma/mature B-cell leukemia. Establishment of such a trial would provide greater potential to answer key treatment issues and ultimately lead to improved outcome for infant ALL.

\section{CONFLICT OF INTEREST}

The authors declare no conflict of interest.

\section{REFERENCES}

1 Linabery AM, Ross JA. Trends in childhood cancer incidence in the US (1992-2004). Cancer 2008; 112: 416-432.

2 Howlader N, Noone AM, Krapcho M, Garshell J, Neyman N, Altekruse SF et al. (eds) SEER Cancer Statistics Review, 1975-2010. National Cancer Institute: Bethesda, MD, 2013. http://seer.cancer.gov/csr/1975_2010/based on November 2012 SEER data submission, posted to the SEER web site.

3 Farber S, Diamond LK. Temporary remissions in acute leukemia in children produced by folic acid antagonist, 4-aminopteroyl-glutamic acid. $N$ Engl J Med 1948; 238: 787-793.

4 Hunger SP, Lu X, Devidas M, Camitta BM, Gaynon PS, Winick NJ et al. Improved survival for children and adolescents with acute lymphoblastic leukemia between 1990 and 2005: a report from the Children's Oncology Group. J Clin Oncol 2012; 30: 1663-1669.

5 O'Leary M, Krailo M, Anderson JR, Reaman GH. Progress in childhood cancer: 50 years of research collaboration, a report from the Children's Oncology Group. Semin Oncol 2008; 35: 484-493.

6 Modan B, Virag I, Modan M. Survival in childhood malignancies: assessment of the influence of age, sex, and tumor type, with emphasis on 'long-term survivors'. J Natl Cancer Inst 1969; 43: 349-363.

7 Zippin C, Cutler SJ, Reeves Jr. WJ, Lum D. Variation in survival among patients with acute lymphocytic leukemia. Blood 1971; 37: 59-72.

8 George SL, Fernbach DJ, Vietti TJ, Sullivan MP, Lane DM, Haggard ME et al. Factors influencing survival in pediatric acute leukemia. The SWCCSG experience, 1958-1970. Cancer 1973; 32: 1542-1553.

9 Pui $\mathrm{CH}$, Behm FG, Downing JR, Hancock ML, Shurtleff SA, Ribeiro RC et al. 11q23/MLL rearrangement confers a poor prognosis in infants with acute lymphoblastic leukemia. J Clin Oncol 1994; 12: 909-915.

10 Silverman LB, McLean TW, Gelber RD, Donnelly MJ, Gilliland DG, Tarbell NJ et al. Intensified therapy for infants with acute lymphoblastic leukemia: results from the Dana-Farber Cancer Institute Consortium. Cancer 1997; 80: 2285-2295.

11 Dordelmann M, Reiter A, Borkhardt A, Ludwig WD, Gotz N, Viehmann S et al. Prednisone response is the strongest predictor of treatment outcome in infant acute lymphoblastic leukemia. Blood 1999; 94: 1209-1217.

12 Reaman G, Zeltzer P, Bleyer WA, Amendola B, Level C, Sather H et al. Acute lymphoblastic leukemia in infants less than one year of age: a cumulative experience of the Children's Cancer Study Group. J Clin Oncol 1985; 3: 1513-1521.

13 Reaman GH, Steinherz PG, Gaynon PS, Bleyer WA, Finklestein JZ, Evans R et al. Improved survival of infants less than 1 year of age with acute lymphoblastic leukemia treated with intensive multiagent chemotherapy. Cancer Treat Rep 1987; 71: 1033-1038.

14 Reaman GH, Sposto R, Sensel MG, Lange BJ, Feusner JH, Heerema NA et al. Treatment outcome and prognostic factors for infants with acute lymphoblastic leukemia treated on two consecutive trials of the Children's Cancer Group. J Clin Oncol 1999; 17: 445-455.

15 Gaynon PS, Angiolillo AL, Carroll WL, Nachman JB, Trigg ME, Sather HN et al. Long-term results of the Children's Cancer Group studies for childhood acute lymphoblastic leukemia 1983-2002: a Children's Oncology Group Report. Leukemia 2010; 24: 285-297.

16 Hilden JM, Dinndorf PA, Meerbaum SO, Sather H, Villaluna D, Heerema NA et al. Analysis of prognostic factors of acute lymphoblastic leukemia in infants: report on CCG 1953 from the Children's Oncology Group. Blood 2006; 108: 441-451.

17 Kaleita TA, Reaman GH, MacLean WE, Sather HN, Whitt JK. Neurodevelopmental outcome of infants with acute lymphoblastic leukemia: a Children's Cancer Group report. Cancer 1999; 85: 1859-1865.

18 Salzer W, Dinndorf P, Dreyer Z, Hilden J, Reaman GH. Analysis of infectious complications in infants with acute lymphoblastic leukemia treated on the Children's Cancer Group Protocol 1953: a report from the Children's Oncology Group. J Pediatr Hematol Oncol 2009; 31: 398-405.

19 Salzer WL, Devidas M, Carroll WL, Winick N, Pullen J, Hunger SP et al. Long-term results of the pediatric oncology group studies for childhood acute lymphoblastic leukemia 1984-2001: a report from the Children's Oncology Group. Leukemia 2010; 24: 355-370.

20 Frankel LS, Ochs J, Shuster JJ, Dubowy R, Bowman WP, Hockenberry-Eaton M et al. Therapeutic trial for infant acute lymphoblastic leukemia: the Pediatric Oncology Group experience (POG 8493). J Pediatr Hematol Oncol 1997; 19: 35-42.

21 Lauer SJ, Camitta BM, Leventhal BG, Mahoney Jr. D, Shuster JJ, Kiefer G et al. Intensive alternating drug pairs after remission induction for treatment of infants with acute lymphoblastic leukemia: a Pediatric Oncology Group pilot study. J Pediatr Hematol Oncol 1998; 20: 229-233.

22 Salzer $W L$, Jones $T L$, Devidas M, Hilden JM, Winick $N$, Hunger $S$ et al. Modifications to induction therapy decrease risk of early death in infants with acute lymphoblastic leukemia treated on Children's Oncology Group P9407. Pediatr Blood Cancer 2012; 59: 834-839.

23 Dreyer ZE, Dinndorf PA, Camitta B, Sather H, La MK, Devidas M et al. Analysis of the role of hematopoietic stem-cell transplantation in infants with acute lymphoblastic leukemia in first remission and MLL gene rearrangements: a report from the Children's Oncology Group. J Clin Oncol 2011; 29: 214-222.

24 Brown P, Hilden JM, Dreyer ZE, Winick NJ, Salzer W, Raetz E et al. Report on excessive induction toxicity in infants with ALL enrolled on COG protocol AALL0631: a Children's Oncology Group study. Blood 2009; 114: 3091.

25 Salzer W, Jones T, Dreyer Z, Gore L, Winick N, Sung L et al. Decreased induction morbidity and mortality with changes to induction therapy in infants with acute lymphoblastic leuekemia enrolled on Children's Oncology Group (COG) trial AALL0631. Pediatr Blood Cancer 2012; 58: 409. 
26 Brown P, Kaeding A, Magoon D, Small D, Jones T, Devidas M et al. Identification of a safe and biologically active dose of the FLT3 inhibitor lestaurtinib in combination with chemotherapy in infants with MLL-rearranged (MLL-R) ALL: a Children's Oncology Group study. Pediatr Blood Cancer 2011; 56: 302B.

27 Sun D, Kaeding A, Magoon D, Jones T, Devidas M, Carroll AJ et al. Safety and biological activity of the FLT3 inhibitor lestaurtinib in infant MLL-rearranged (MLL-r) ALL: Children's Oncology Group protocol AALL0631. J Clin Oncol 2012; 30(15_Suppl): 9548.

28 Stam RW, den Boer ML, Schneider P, Nollau P, Horstmann M, Beverloo HB et al. Targeting FLT3 in primary MLL-gene-rearranged infant acute lymphoblastic leukemia. Blood 2005; 106: 2484-2490.

29 Taketani T, Taki T, Sugita K, Furuichi Y, Ishii E, Hanada R et al. FLT3 mutations in the activation loop of tyrosine kinase domain are frequently found in infant ALL with MLL rearrangements and pediatric ALL with hyperdiploidy. Blood 2004; 103: $1085-1088$

30 Stam RW, den Boer ML, Schneider P, Meier M, Beverloo HB, Pieters R. D-HPLC analysis of the entire FLT3 gene in MLL rearranged and hyperdiploid acute lymphoblastic leukemia. Haematologica 2007; 92: 1565-1568.

31 Emerenciano $M$, Menezes J, Vasquez ML, Zalcberg I, Thuler LC, Pombo-de-Oliveira MS. Clinical relevance of FLT3 gene abnormalities in Brazilian patients with infant leukemia. Leuk Lymphoma 2008; 49: 2291-2297.

32 Chen CS, Sorensen PH, Domer PH, Reaman GH, Korsmeyer SJ, Heerema NA et al. Molecular rearrangements on chromosome 11q23 predominate in infant acute lymphoblastic leukemia and are associated with specific biologic variables and poor outcome. Blood 1993; 81: 2386-2393.

33 Rubnitz JE, Link MP, Shuster JJ, Carroll AJ, Hakami N, Frankel LS et al. Frequency and prognostic significance of HRX rearrangements in infant acute lymphoblastic leukemia: a Pediatric Oncology Group study. Blood 1994; 84: 570-573.

34 Taki T, Ida K, Bessho F, Hanada R, Kikuchi A, Yamamoto K et al. Frequency and clinical significance of the MLL gene rearrangements in infant acute leukemia. Leukemia 1996; 10: 1303-1307.

35 Isoyama K, Eguchi M, Hibi S, Kinukawa N, Ohkawa H, Kawasaki H et al. Risk-directed treatment of infant acute lymphoblastic leukaemia based on early assessment of MLL gene status: results of the Japan Infant Leukaemia Study (MLL96). Br J Haematol 2002; 118: 999-1010.

36 Kosaka Y, Koh K, Kinukawa N, Wakazono Y, Isoyama K, Oda T et al. Infant acute lymphoblastic leukemia with MLL gene rearrangements: outcome following intensive chemotherapy and hematopoietic stem cell transplantation. Blood 2004; 104: 3527-3534.

37 Tomizawa D, Koh K, Sato T, Kinukawa N, Morimoto A, Isoyama K et al. Outcome of risk-based therapy for infant acute lymphoblastic leukemia with or without an MLL gene rearrangement, with emphasis on late effects: a final report of two consecutive studies, MLL96 and MLL98, of the Japan Infant Leukemia Study Group. Leukemia 2007; 21: 2258-2263.

38 Nagayama J, Tomizawa D, Koh K, Nagatoshi Y, Hotta N, Kishimoto T et al. Infants with acute lymphoblastic leukemia and a germline MLL gene are highly curable with use of chemotherapy alone: results from the Japan Infant Leukemia Study Group. Blood 2006; 107: 4663-4665.

39 Tomizawa D, Koh K, Hirayama M, Miyamura T, Hatanaka M, Saikawa Y et al. Outcome of recurrent or refractory acute lymphoblastic leukemia in infants with MLL gene rearrangements: a report from the Japan Infant Leukemia Study Group. Pediatr Blood Cancer 2009; 52: 808-813.

40 Koh K, Tomizawa D, Saito AM, Watanabe T, Ogawa A, Sato T et al. Early phase administration of hematopoietic stem cell transplantation to prevent early relapse for infants with acute lymphoblastic leukemia and MLL gene rearrangement; a report from the Japanese Pediatric Leukemia/Lymphoma Study Group (JPLSG) trial MLL03. Blood 2010; 116: 529

41 Miyamura T, Koh K, Tomizawa D, Sato T, Kato K, Sugita K et al. Nation-wide survey of relapsed infantile acute lymphoblastic leukemia in Japan: treatment and outcome from the Japanese Pediatric Leukemia/Lymphoma Study Group (JPLSG) MLL03 study. Blood 2010; 116: 1025

42 Chessells JM, Eden OB, Bailey CC, Lilleyman JS, Richards SM. Acute lymphoblastic leukaemia in infancy: experience in MRC UKALL trials. Report from the Medical Research Council Working Party on Childhood Leukaemia. Leukemia 1994; 8: $1275-1279$.

43 Chessells JM, Harrison CJ, Watson SL, Vora AJ, Richards SM. Treatment of infants with lymphoblastic leukaemia: results of the UK Infant Protocols 1987-1999. Br J Haematol 2002; 117: 306-314.

44 Pieters R, Schrappe M, De Lorenzo P, Hann I, De Rossi G, Felice M et al. A treatment protocol for infants younger than 1 year with acute lymphoblastic leukaemia (Interfant-99): an observational study and a multicentre randomised trial. Lancet 2007; 370: 240-250.

45 Mann G, Attarbaschi A, Schrappe M, De Lorenzo P, Peters C, Hann I et al. Improved outcome with hematopoietic stem cell transplantation in a poor prognostic subgroup of infants with mixed-lineage-leukemia (MLL)-rearranged acute lymphoblastic leukemia: results from the Interfant-99 Study. Blood 2010; 116: 2644-2650.

46 van der Linden $\mathrm{MH}$, Valsecchi MG, De Lorenzo P, Moricke A, Janka G, Leblanc TM et al. Outcome of congenital acute lymphoblastic leukemia treated on the Interfant-99 protocol. Blood 2009; 114: 3764-3768.

47 Van der Velden VH, Corral L, Valsecchi MG, Jansen MW, De Lorenzo P, Cazzaniga $G$ et al. Prognostic significance of minimal residual disease in infants with acute lymphoblastic leukemia treated within the Interfant-99 protocol. Leukemia 2009; 23: 1073-1079.

48 Marco F, Bureo E, Ortega JJ, Badell I, Verdaguer A, Martinez A et al. High survival rate in infant acute leukemia treated with early high-dose chemotherapy and stem-cell support. Groupo Espanol de Trasplante de Medula Osea en Ninos. J Clin Oncol 2000; 18: 3256-3261.

49 Jacobsohn DA, Hewlett B, Morgan E, Tse W, Duerst RE, Kletzel M. Favorable outcome for infant acute lymphoblastic leukemia after hematopoietic stem cell transplantation. Biol Blood Marrow Transplant 2005; 11: 999-1005.

50 Sanders JE, Im HJ, Hoffmeister PA, Gooley TA, Woolfrey AE, Carpenter PA et al. Allogeneic hematopoietic cell transplantation for infants with acute lymphoblastic leukemia. Blood 2005; 105: 3749-3756.

51 Corker E, Astwood E, Williams J, Vora A. Treosulphan-based radiation-free myeloablative conditioning for allogeneic transplant in infant acute lymphoblastic leukaemia. Br J Haematol 2012; 159: 104-106.

52 Bordigoni P, Benz-Lemoine E, Vannier JP, Fischer A. Bone marrow transplantation following busulfan, cyclophosphamide and high dose cytosine-arabinoside as treatment for infants with translocation $(4 ; 11)$ acute leukaemia. $\mathrm{Br} J$ Haematol 1989; 72: 293-294.

53 von Bueltzingsloewen A, Esperou-Bourdeau H, Souillet G, Demeocq F, Mechinaud-Lacroix F, Michel $G$ et al. Allogeneic bone marrow transplantation following a busulfan-based conditioning regimen in young children with acute lymphoblastic leukemia: a Cooperative Study of the Societe Francaise de Greffe de Moelle. Bone Marrow Transplant 1995; 16: 521-527.

54 Ayas M, Belgaumi A, Al-Mahr M, Al-Jefri A, Solh H, Leung W. Allogeneic BMT for infantile acute leukemia: what is the optimal conditioning regimen? Bone Marrow Transplant 2002; 29: 630; author reply 631.

55 Pui CH, Gaynon PS, Boyett JM, Chessells JM, Baruchel A, Kamps W et al. Outcome of treatment in childhood acute lymphoblastic leukaemia with rearrangements of the 11q23 chromosomal region. Lancet 2002; 359: 1909-1915.

56 Ziemin-van der Poel S, McCabe NR, Gill HJ, Espinosa 3rd R, Patel Y, Harden A et al. Identification of a gene, MLL, that spans the breakpoint in $11 \mathrm{q} 23$ translocations associated with human leukemias. Proc Natl Acad Sci USA 1991; 88 10735-10739.

57 Cimino G, Moir DT, Canaani O, Williams K, Crist WM, Katzav S et al. Cloning of ALL-1, the locus involved in leukemias with the $t(4 ; 11)(q 21 ; q 23), t(9 ; 11)(p 22 ; q 23)$, and $t(11 ; 19)(q 23 ; p 13)$ chromosome translocations. Cancer Res 1991; 51: 6712-6714

58 Driessen EM, van Roon EH, Spijkers-Hagelstein JA, Schneider $\mathrm{P}$, de Lorenzo $\mathrm{P}$ Valsecchi MG et al. Frequencies and prognostic impact of RAS mutations in MLLrearranged acute lymphoblastic leukemia in infants. Haematologica 2013; 98: 937-944.

59 Suminoe A, Matsuzaki A, Hattori $\mathrm{H}$, Koga $\mathrm{Y}$, Kinukawa $\mathrm{N}$, Ishii $\mathrm{E}$ et al. mRNA expression of apoptosis-associated genes in infant acute lymphoblastic leukemia: low Fas expression is an independent predictor for poor prognosis. Leukemia 2004; 18: 365-368.

60 Stam RW, Schneider P, Hagelstein JA, van der Linden MH, Stumpel DJ, de Menezes RX et al. Gene expression profiling-based dissection of MLL translocated and MLL germline acute lymphoblastic leukemia in infants. Blood 2010; 115: $2835-2844$

61 Kang H, Wilson CS, Harvey RC, Chen IM, Murphy MH, Atlas SR et al. Gene expression profiles predictive of outcome and age in infant acute lymphoblastic leukemia: a Children's Oncology Group study. Blood 2012; 119: 1872-1881.

62 Stumpel DJ, Schneider P, van Roon EH, Pieters R, Stam RW. Absence of global hypomethylation in promoter hypermethylated Mixed Lineage Leukaemiarearranged infant acute lymphoblastic leukaemia. Eur J Cancer 2013; 49: 175-184.

63 Stumpel DJ, Schneider P, van Roon EH, Boer JM, de Lorenzo P, Valsecchi MG et al. Specific promoter methylation identifies different subgroups of MLL-rearranged infant acute lymphoblastic leukemia, influences clinical outcome, and provides therapeutic options. Blood 2009; 114: 5490-5498.

64 Schafer E, Irizarry R, Negi S, Mclntyre E, Small D, Figueroa ME et al. Promoter hypermethylation in MLL-r infant acute lymphoblastic leukemia: biology and therapeutic targeting. Blood 2010; 115: 4798-4809. 
65 Stumpel DJ, Schotte D, Lange-Turenhout EA, Schneider P, Seslija L, de Menezes RX et al. Hypermethylation of specific microRNA genes in MLL-rearranged infant acute lymphoblastic leukemia: major matters at a micro scale. Leukemia 2011; 25: 429-439.

66 Nishi M, Eguchi-Ishimae M, Wu Z, Gao W, Iwabuki H, Kawakami S et al. Suppression of the let-7b microRNA pathway by DNA hypermethylation in infant acute lymphoblastic leukemia with MLL gene rearrangements. Leukemia 2013; 27: 389-397.

67 Stumpel DJ, Schneider P, Seslija L, Osaki H, Williams O, Pieters R et al. Connectivity mapping identifies HDAC inhibitors for the treatment of $t(4 ; 11)$ positive infant acute lymphoblastic leukemia. Leukemia 2012; 26: 682-692.

68 Robinson BW, Behling KC, Gupta M, Zhang AY, Moore JS, Bantly AD et al. Abundant anti-apoptotic BCL-2 is a molecular target in leukaemias with $\mathrm{t}(4 ; 11)$ translocation. Br J Haematol 2008; 141: 827-839.

69 Stam RW, Den Boer ML, Schneider P, de Boer J, Hagelstein J, Valsecchi MG et al. Association of high-level MCL-1 expression with in vitro and in vivo prednisone resistance in MLL-rearranged infant acute lymphoblastic leukemia. Blood 2010 115: 1018-1025.

70 Urtishak KA, Edwards AY, Wang LS, Hudome A, Robinson BW, Barrett JS et al. Potent obatoclax cytotoxicity and activation of triple death mode killing across infant acute lymphoblastic leukemia. Blood 2013; 121: 2689-2703.

71 Jayanthan A, Incoronato A, Singh A, Blackmore C, Bernoux D, Lewis V et al. Cytotoxicity, drug combinability, and biological correlates of ABT-737 against acute lymphoblastic leukemia cells with MLL rearrangement. Pediatr Blood Cancer 2011; 56: 353-360.

72 Qazi S, Uckun FM. Gene expression profiles of infant acute lymphoblastic leukaemia and its prognostically distinct subsets. Br J Haematol 2010; 149: 865-873.

73 Urtishak KA, Wang LS, Teachey DT, Sarah TK, Barrett JS, Chen IM et al. $\mathrm{PIK} 3 / \mathrm{AKT} / \mathrm{mTOR}$ signaling is a significant druggable pathway in infant acute lymphoblastic leukemia (ALL). Blood 2013; 122: 1669.

74 Carol H, Szymanska B, Evans K, Boehm I, Houghton PJ, Smith MA et al. The anti-CD19 antibody-drug conjugate SAR3419 prevents hematolymphoid relapse postinduction therapy in preclinical models of pediatric acute lymphoblastic leukemia. Clinical Cancer Res 2013; 19: 1795-1805.

75 Lock RB, Richmond J, High L, Hernan C, Evans K, Mendomo AM et al. Effective targeting of the P53/MDM2 axis in preclinical models of infant MLL-rearranged acute lymphoblastic leukemia. Blood 2013; 122: 71.

76 Spijkers-Hagelstein JA, Schneider P, Hulleman E, de Boer J, Williams O, Pieters R et al. Elevated S100A8/S100A9 expression causes glucocorticoid resistance in MLL-rearranged infant acute lymphoblastic leukemia. Leukemia 2012; 26: 1255-1265.

77 Spijkers-Hagelstein JA, Mimoso Pinhancos S, Schneider P, Pieters R, Stam RW. Src kinase-induced phosphorylation of annexin A2 mediates glucocorticoid resistance in MLL-rearranged infant acute lymphoblastic leukemia. Leukemia 2013; 27: 1063-1071.

78 Spijkers-Hagelstein JAP, Pinhanços SS, Schneider P, Pieters R, Stam RW. Chemical genomic screening identifies LY294002 as a modulator of glucocorticoid resistance in MLL-rearranged infant ALL. Leukemia 2013; e-pub ahead of print 20 August 2013; doi:10.1038/leu.2013.245.

79 Sison EA, Rau RE, McIntyre E, Li L, Small D, Brown P. MLL-rearranged acute lymphoblastic leukaemia stem cell interactions with bone marrow stroma promote survival and therapeutic resistance that can be overcome with CXCR4 antagonism. Br J Haematol 2013; 160: 785-797.

80 Daigle SR, Olhava EJ, Therkelsen CA, Majer CR, Sneeringer CJ, Song J et al. Selective killing of mixed lineage leukemia cells by a potent small-molecule DOT1L inhibitor. Cancer Cell 2011; 20: 53-65.

81 Daigle SR, Olhava EJ, Therkelsen CA, Basavapathruni A, Jin L, Boriack-Sjodin PA et al. Potent inhibition of DOT1L as treatment of MLL-fusion leukemia. Blood 2013; 122 1017-1025.

82 Grembecka J, He S, Shi A, Purohit T, Muntean AG, Sorenson RJ et al. Menin-MLL inhibitors reverse oncogenic activity of MLL fusion proteins in leukemia. Nat Chem Biol 2012; 8: 277-284.

83 Accordi B, Galla L, Milani G, Curtarello M, Serafin V, Lissandron V et al. AMPK inhibition enhances apoptosis in MLL-rearranged pediatric B-acute lymphoblastic leukemia cells. Leukemia 2013; 27: 1019-1027.

84 Sung NS, Crowley Jr WF, Genel M, Salber P, Sandy L, Sherwood LM et al. Central challenges facing the national clinical research enterprise. JAMA 2003, 289: 1278-1287.

85 Schrappe M, Hunger SP, Pui CH, Saha V, Gaynon PS, Baruchel A et al. Outcomes after induction failure in childhood acute lymphoblastic leukemia. N Engl J Med 2012; 366: 1371-1381.

86 Leung W, Hudson M, Zhu Y, Rivera GK, Ribeiro RC, Sandlund JT et al. Late effects in survivors of infant leukemia. Leukemia 2000; 14: 1185-1190.

87 Felix CA. Infant leukemia 2010: a call to action for the west and the 'four Asian Tigers'. Pediatr Blood Cancer 2010; 55: 1247-1249.
88 Conter V, Arico M, Basso G, Biondi A, Barisone E, Messina C et al. Long-term results of the Italian Association of Pediatric Hematology and Oncology (AIEOP) Studies 82, 87, 88, 91 and 95 for childhood acute lymphoblastic leukemia. Leukemia 2010; 24: 255-264.

89 Moricke A, Zimmermann M, Reiter A, Henze G, Schrauder A, Gadner H et al. Long-term results of five consecutive trials in childhood acute lymphoblastic leukemia performed by the ALL-BFM study group from 1981 to 2000. Leukemia 2010; 24: 265-284.

90 Vilmer E, Suciu S, Ferster A, Bertrand Y, Cave H, Thyss A et al. Long-term results of three randomized trials $(58831,58832,58881)$ in childhood acute lymphoblastic leukemia: a CLCG-EORTC report. Children Leukemia Cooperative Group. Leukemia 2000; 14: 2257-2266.

91 Harms DO, Janka-Schaub GE. Co-operative study group for childhood acute lymphoblastic leukemia (COALL): long-term follow-up of trials 82, 85, 89 and 92. Leukemia 2000; 14: 2234-2239.

92 Jabali Y, Stary J, Hak J, Blazek B, Hrstkova H, Mihal V et al. Acute lymphoblastic leukemia in infants: a decade of experience in the Czech Republic. Med Pediatr Oncol 2000; 35: 493-495.

93 Stary J, Jabali Y, Trka J, Hrusak O, Gajdos P, Hrstkova $\mathrm{H}$ et al. Long-term results of treatment of childhood acute lymphoblastic leukemia in the Czech Republic Leukemia 2010; 24: 425-428.

94 Kamps WA, van der Pal-de Bruin KM, Veerman AJ, Fiocco M, Bierings M, Pieters $R$. Long-term results of Dutch Childhood Oncology Group studies for children with acute lymphoblastic leukemia from 1984 to 2004. Leukemia 2010; 24 309-319.

95 Silverman LB, Stevenson KE, O'Brien JE, Asselin BL, Barr RD, Clavell L et al. Long-term results of Dana-Farber Cancer Institute ALL Consortium protocols for children with newly diagnosed acute lymphoblastic leukemia (1985-2000). Leukemia 2010; 24: 320-334.

96 Donadieu J, Auclerc MF, Baruchel A, Leblanc T, Landman-Parker J, Perel Y et al. Critical study of prognostic factors in childhood acute lymphoblastic leukaemia: differences in outcome are poorly explained by the most significant prognostic variables. Fralle group. French Acute Lymphoblastic Leukaemia study group. Br J Haematol 1998; 102: 729-739.

97 Oudot C, Auclerc MF, Levy V, Porcher R, Piguet C, Perel Y et al. Prognostic factors for leukemic induction failure in children with acute lymphoblastic leukemia and outcome after salvage therapy: the FRALLE 93 study. J Clin Oncol 2008; 26: 1496-1503.

98 Stark B, Nirel R, Avrahami G, Abramov A, Attias D, Ballin A et al. Long-term results of the Israeli National Studies in childhood acute lymphoblastic leukemia: INS 84 89 and 98. Leukemia 2010; 24: 419-424.

99 Horibe K, Hara J, Yagi K, Tawa A, Komada Y, Oda M et al. Prognostic factors in childhood acute lymphoblastic leukemia in Japan. Japan Association of Childhood Leukemia Study. Int J Hematol 2000; 72: 61-68.

100 Tsurusawa M, Shimomura Y, Asami K, Kikuta A, Watanabe A, Horikoshi Y et al. Long-term results of the Japanese Childhood Cancer and Leukemia Study Group studies $811,841,874$ and 911 on childhood acute lymphoblastic leukemia. Leukemia 2010; 24: 335-344.

101 Matsuzaki A, Ishii E, Okamura J, Eguchi H, Yoshida N, Yanai F et al. Treatment of high-risk acute lymphoblastic leukemia in children using the AL851 and ALHR88 protocols: a report from the Kyushu-Yamaguchi Children's Cancer Study Group in Japan. Med Pediatr Oncol 1996; 26: 10-19.

102 Yeoh AE, Ariffin H, Chai EL, Kwok CS, Chan YH, Ponnudurai $\mathrm{K}$ et al. Minimal residual disease-guided treatment deintensification for children with acute lymphoblastic leukemia: results from the Malaysia-Singapore acute lymphoblastic leukemia 2003 study. J Clin Oncol 2012; 30: 2384-2392.

103 Gustafsson G, Schmiegelow K, Forestier E, Clausen N, Glomstein A Jonmundsson $\mathrm{G}$ et al. Improving outcome through two decades in childhood ALL in the Nordic countries: the impact of high-dose methotrexate in the reduction of CNS irradiation. Nordic Society of Pediatric Haematology and Oncology (NOPHO). Leukemia 2000; 14: 2267-2275.

104 Ribera JM, Ortega JJ, Oriol A, Bastida P, Calvo C, Perez-Hurtado JM et al. Comparison of intensive chemotherapy, allogeneic, or autologous stem-cell transplantation as postremission treatment for children with very high risk acute lymphoblastic leukemia: PETHEMA ALL-93 Trial. J Clin Oncol 2007; 25: $16-24$

105 Campbell M, Salgado C, Quintana J, Becker A, Vargas L, Cabrera ME et al. Improved outcome for acute lymphoblastic leukemia in children of a developing country: results of the Chilean National Trial PINDA 87. Med Pediatr Oncol 1999; 33: 88-94.

106 Pui CH, Simone JV, Hancock ML, Evans WE, Williams DL, Bowman WP et al. Impact of three methods of treatment intensification on acute lymphoblastic leukemia in children: long-term results of St Jude total therapy study X. Leukemia 1992; 6: 150-157. 


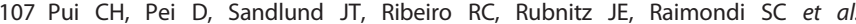
Long-term results of St Jude Total Therapy Studies 11, 12, 13A, 13B, and 14 for childhood acute lymphoblastic leukemia. Leukemia 2010; 24: $371-382$

108 Tsuchida M, Ikuta K, Hanada R, Saito T, Isoyama K, Sugita K et al. Long-term follow-up of childhood acute lymphoblastic leukemia in Tokyo Children's Cancer Study Group 1981-1995. Leukemia 2000; 14: 2295-2306.

109 Liang DC, Yang CP, Lin DT, Hung IJ, Lin KH, Chen JS et al. Long-term results of Taiwan Pediatric Oncology Group studies 1997 and 2002 for childhood acute lymphoblastic leukemia. Leukemia 2010; 24: 397-405.
110 Mitchell C, Richards S, Harrison CJ, Eden T. Long-term follow-up of the United Kingdom medical research council protocols for childhood acute lymphoblastic leukaemia, 1980-2001. Leukemia 2010; 24: 406-418.

111 Biondi A, Rizzari C, Valsecchi MG, De Lorenzo P, Arico M, Basso G et al. Role of treatment intensification in infants with acute lymphoblastic leukemia: results of two consecutive AIEOP studies. Haematologica 2006; 91: 534-537.

(c) (1) $\odot$ This work is licensed under a Creative Commons AttributionBY NC ND NonCommercial-NoDerivs 3.0 Unported License. To view a copy of this license, visit http://creativecommons.org/licenses/by-nc-nd/3.0/ 